
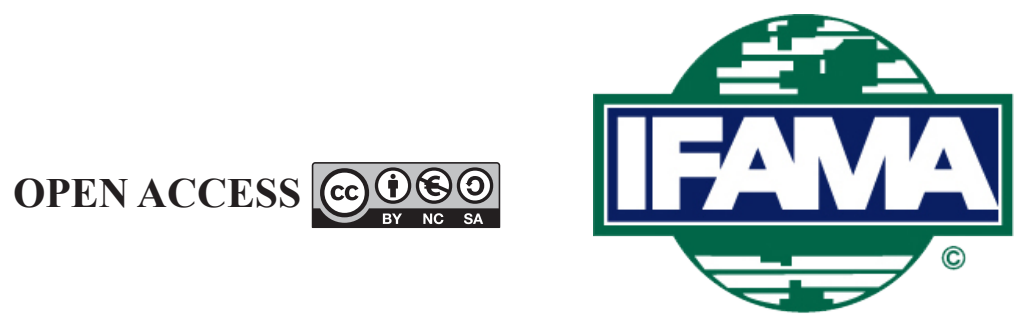

International Food and Agribusiness Management Review

Volume 24, Issue 3, 2021; DOI: 10.22434/IFAMR2020.0113

Received: 17 July 2020 / Accepted: 16 November 2020

\title{
Chinese consumer preferences for organic labels on Oolong tea: evidence from a choice experiment
}

\section{RESEARCH ARTICLE}

\author{
Xiaoke Yang ${ }^{\mathrm{a}}$, Qiuhua Chen ${ }^{\mathrm{b}}$, Nenmei Lin ${ }^{\mathrm{c}}$, Mengzhu Han ${ }^{\mathrm{c}}$, Qian Chen ${ }^{\oplus \mathrm{d}}$, Qiuqin Zheng ${ }^{\mathrm{a}}$, \\ Bin $\mathrm{Gao}^{\mathrm{e}}$, Fengbo Liu ${ }^{\mathrm{f}}$ and Zhongyue $\mathrm{Xu}^{\oplus \mathrm{Db}, \mathrm{f}, \mathrm{g}}$ \\ ${ }^{a}$ PhD student, ${ }^{b}$ Professor, ${ }^{c}$ Graduate student, College of Management, Fujian \\ Agriculture and Forestry University, Fuzhou 350002, China P.R. \\ ${ }^{d}$ Associate Professor, College of Economics, Fujian Agriculture and Forestry University, Fuzhou 350002, China P.R. \\ ${ }^{e}$ Associate Professor, School of Business, Guangxi University for Nationalities, Nanning 530006, China P.R. \\ ${ }_{f}$ Associate Professor, Research Center for Ecological Civilization, Fujian \\ Social Science Research Base, Fuzhou 350002, China P.R. \\ ${ }^{g}$ Associate Professor, School of Business Administration, South China \\ University of Technology, Guangzhou 510641, China P.R.
}

\begin{abstract}
Repeated food scandals in China have prompted growing consumer consciousness on food safety and health. Organic food, considered to be of higher quality, is being increasingly demanded by Chinese consumers. This study examines preferences for organic labels to provide insight on the sustainable development of the Oolong tea industry. Research was conducted using the choice experiment (CE) method in Fujian and Guangdong Provinces. The results demonstrate that place of origin, organic label, and brand attributes are all significant factors affecting the purchase of Oolong. Also, people demonstrated significantly positive attitudes toward organic labels and preferred Oolong tea from Fujian Province to those from Guangdong Province and Taiwan. Increasing trust can enhance consumer preference and willingness to pay (WTP) for organic labels. Contrary to previous studies, people have a higher WTP for Chinese organic labels than Japanese and American ones. This is probably because respondents are more familiar with domestic Oolong tea and trust more in Chinese organic certification. This provides an opportunity for domestic producers to tailor their organic food labels and better satisfy consumer demands. These findings suggest that the Chinese government should take more responsibility for reducing food-related fraud and thus improve consumer trust regarding organic food.
\end{abstract}

Keywords: Oolong tea, organic food, consumer preference, choice experiment JEL code: Q01

(ํ) Corresponding author: 000q271007@fafu.edu.cn / 00XM818001@fafu.edu.cn 


\section{Introduction}

Pesticides and mineral fertilizers might enhance the productivity of agriculture, whereas more and more studies have revealed that these chemicals remain in food and harm human health (Carvalho, 2006; Yin et al., 2018a). Organic food is critically demanded by consumers as it is perceived as a healthier and safer alternative (Bryła, 2016; Goetzke et al., 2014). Recently, food scandals in China have evoked strong awareness of food safety and health concerns by Chinese consumers (Chen et al., 2019b; Zhang et al., 2014). After the melamine incident in 2008, many studies determined that people were willing to pay a premium for imported organic food (Quan et al., 2018; Wu et al., 2014). Demand for organic food has amplified in recent years (Scozzafava et al., 2020; Willer and Lernoud, 2019). China has the third-largest land area for organic farming (2.3 megahectares (Mha) worldwide, following Australia (27.1 Mha) and Argentina (3.0 Mha) (Willer and Lernoud, 2019). Considering the recent population expansion and economic growth, massive domestic demand for organic food is apparent (Bekele et al., 2017; Willer and Lernoud, 2019).

Tea is one of the most popular drinks in the world, and China is the largest tea producer globally (Gunathilaka and Tularam, 2016). Oolong tea is unique to China (Chen et al., 2010), and its yield ranked the third-largest of all kinds of tea in 2018. Additionally, the export price of Oolong tea is higher than other tea products (Mei, 2020). Driven by higher economic profits, farmers use massive amounts of mineral fertilizers and pesticides to promote yields. With growing concerns about heavy metals and other chemical residues in Oolong tea (Chen et al., 2020), the Chinese government issued an official campaign to ensure zero growth in pesticide use by 2020 to reduce the pollution caused by agricultural chemicals (Department of Agriculture, 2015). Local governments reduce pesticide use by offering subsidies to tea farmers. However, it is uncertain how long this trend will last, with subsidies being discontinued after 2020. To achieve sustainable development of the tea industry, efforts should go beyond the production side (Zhu et al., 2013). With the development of economic incentives regulated by governments, consumers increasingly pay attention to environmental issues (Ghvanidze et al., 2016). According to Ghvanidze et al. (2016), environmental consciousness is also reflected in consumption behaviors, in which consumers contribute to a sustainable society by choosing environmentally friendly food. Taken together, an effective way to solve environmental challenges in the Oolong tea industry is to promote organic Oolong tea consumption, which encourages farmers and companies to go green.

Organic food is a typical credence good, and the organic attribute is often indicated through an organic label (Yin et al., 2019b). Before China implemented domestic official organic certification, organic food in the market was imported (Zheng et al., 2013). An apparent barrier that restrains organic market share expansion is higher prices (Xie et al., 2015). Developed countries as well as most developing countries have their own organic labels indicating the organic standards of local regions (Thøgersen et al., 2019). Chinese food safety scandals have led to market chaos, which resulted in distrust of domestic organic labels (Wu et al., 2014). Therefore, organic labels from other regions are prevalent in the Chinese organic market (Yin et al., 2019a). With organic labels of different regions coexisting in the Chinese market (Yin et al., 2019a), the attitudes toward various organic labels have emerged in a few studies, and the results indicate that Chinese consumers prefer organic labels from more developed regions (Li et al., 2015; Yin et al., 2016).

Organic food is a Western invention that regards it to be more sustainable than conventional food (Lockeretz, 2007; Thøgersen and Zhou, 2012); however, this triggers a question - do Chinese consumers always prefer organic labels from developed regions, even for traditional Chinese or unique foods? As the representative cash crop in southern China, few studies have measured the evaluation of organic Oolong tea with multiple organic labels among Chinese consumers. Many studies related to organic food preferences have been performed under the theory of panned behavior, considering consumer characteristics such as self-value, social norms, etc. (Qi and Ploeger, 2019; Yadav and Pathak, 2016; Zhang et al., 2018). However, when choosing products, consumer characteristics as well as product attributes need to be considered (Boncinelli et al., 2019). Compared with other approaches, a choice experiment (CE) approach can measure decisive attributes of preference for products and provide much more information regarding when to detect purchase 
intention (Ghvanidze et al., 2016). Research on Chinese consumption for typical organic foods using the $\mathrm{CE}$ approach is relatively scarce (Xu et al., 2015). Taken together, this study values consumers' preferences for different organic labels of Oolong tea using the CE approach.

Previous research has indicated that trust is significant in purchasing decisions (Daugbjerg et al., 2014; Lassoued and Hobbs, 2014). Low trust is associated with a lower evaluation of labeling itself, which further results in reducing purchase intention (Tonkin et al., 2016). It seems that consumers are inclined to believe independent third parties to make certifications (Albersmeier et al., 2010). Many types of organic labels exist on the Chinese market, and whether or not trust in organic labels impacts the organic food market has aroused researchers' interest. Chen et al. (2019a) measured the interaction effect of organic labels and trust and showed that consumers put more trust in organic labels from developed countries or regions. The interaction effect of attributes can reveal the relationship between product attributes. However, research on the interaction between trust and typical Chinese organic product consumption is still relatively scarce and needs to be explored in more depth.

In 2019, the total domestic sales of Oolong tea reached $\$ 4.23$ billion and continue to show an increasing trend (Mei, 2020). Although total domestic tea sales are quite large, research on consumer preferences for organic tea is relatively scarce, considering that food safety has become a major concern among Chinese consumers (Zhou et al., 2014) as well as the tremendous importance of the tea industry. Accordingly, this study aims to measure Chinese consumers' preference for organic Oolong tea. This research makes several contributions to understanding the question of whether different organic labels influence purchase decisions on Oolong tea products. First, this study investigates consumer preferences for various organic Oolong tea labels with important attributes (i.e. brand, origin place, and price). Second, Qi and Ploeger (2019) investigated consumers' intentions toward purchasing green foods and found that adding personal characteristic factors increased the percentage of explained purchase intention variances. Thus, this study determined the impact of consumer characteristics on preferences for organic Oolong tea. Third, many studies have pointed out that trust is an important key to determining willingness to pay (WTP) for organic food (Krystallis and Chryssohoidis, 2005; Nuttavuthisit and Thøgersen, 2017). This study measures subjective knowledge and trust interaction effects with chosen attributes when purchasing Oolong tea and gains accurate WTP values for various organic labels.

\section{Design and methods}

To measure product preferences, CE is often adopted (Chen et al., 2019a; Gao et al., 2019), as it can narrow bias by grouping given attributes into different components (Louviere et al., 2000). This study can further estimate the effects of objective attributes and trust attitudes using conjoint $\mathrm{CE}$. Results of conjoint $\mathrm{CE}$ are more accurate as they are less influenced by social desirability bias (Auger and Devinney, 2007).

\subsection{Attribute selection}

The attributes chosen were based on real market research and panel discussions. Firstly, the research team was divided into two groups. Group one went to the real tea market in Fuzhou (the capital of Fujian Province) in March 2019 to investigate the current prevalent organic labels on Oolong tea. Because e-commerce is one of the most important trading channels in China, group two searched the biggest e-commerce website (Taobao) for organic labels in the 50 top-selling shops. Other attributes were selected based on previous literature (Hoek et al., 2017; Thøgersen et al., 2019). Finally, this study specified four attributes, which are shown in Table 1.

The main locations of Oolong tea plantations are Fujian, Guangdong, and Taiwan (Chen and Yang, 2017). People's familiarity with this product influenced the effects of these attributes (Lähteenmäki, 2013). Thus, this study chose these three regions to narrow consumer bias. In addition, in reality, tea companies like to make different kinds of organic certifications for two purposes, i.e. to enter both domestic and foreign markets 
Table 1. Product attributes and levels in the choice experiment.

\begin{tabular}{lll}
\hline Attributes & Number of levels & Levels \\
\hline Place of origin & 3 & Produced in Fujian \\
& & Produced in Guangdong \\
& & Produced in Taiwan \\
Organic label & 4 & None \\
& & Chinese organic label \\
& & Japanese organic label \\
& 2 & United States organic label \\
Brand & 4 & Regional brand \\
& & National brand \\
Price ${ }^{1}$ & & 13.0 USD per $250 \mathrm{~g}$ \\
& & 14.3 USD per $250 \mathrm{~g}$ \\
& & 15.6 USD per $250 \mathrm{~g}$ \\
\hline 1 USD $=6.99$ RMB (renminbi). & & 16.9 USD per $250 \mathrm{~g}$
\end{tabular}

(Chen et al., 2019a) and to use multiple logos or labels as a certification of quality (Bai et al., 2013). Thus, Chinese consumers can buy Oolong tea with different countries' organic labels in the domestic market. Japan is the largest importer of Chinese Oolong tea, so companies are inclined to use Japanese organic labels (JAPLs) for export to Japan. Several recent studies have demonstrated that Chinese consumers showed a higher preference for organic labels from developed countries (Chen et al., 2019a; Yin et al., 2019a). In this research, the US organic label (USL) was chosen as the representative to examine consumer attitudes. Thus, Chinese organic labels (CHILs), JAPLs, and USLs were finally chosen. It should be noted that Oolong tea with JAPL and USL also is produced in the three Chinese provinces. The various organic labels are shown in Figure 1. This study also set the 'none' label to represent the conventional Oolong tea product. Brand is one of the essential factors that affects consumer consumption decisions. Usually, the national brand (NAB) is considered to be a sign of higher quality and safety compared to regional brands (Enneking et al., 2007). However, due to the different tea-drinking habits from region to region, regional brands (RGBs) might be more accepted by local consumers than NABs. To our knowledge, few studies compare the effects of the NAB and RGBs on Chinese foods. The range of effective subsides or taxes was between 10 and $20 \%$. Considering the higher price of organic products, four levels were set in the price attribute, including $\$ 13.00$ per $250 \mathrm{~g}$ (the average price of a conventional product), and 10, 20 and 30\% higher. The average price of conventional Oolong tea was set based on the self-drinking type product available in stores, which is also consistent with the findings of Chen et al. (2016).
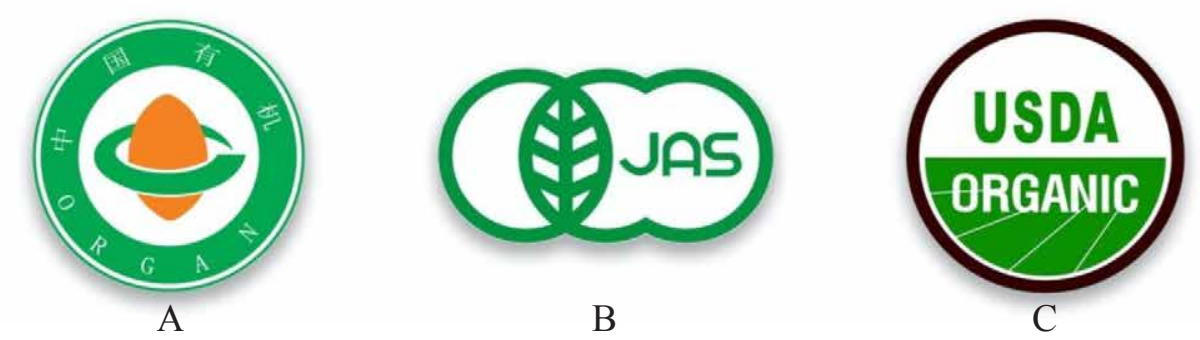

Figure 1. (A) Chinese organic label, (B) Japanese organic label, (C) US organic label. 


\subsection{Experimental design}

The accuracy of CE largely depends on the structure of profiles, which means that designated profiles should explain the variance of the attributes to a large extent while generating as few random errors as possible (Greiner et al., 2014; Yao et al., 2018). This study provided an opt-out option (i.e. neither option A nor option $\mathrm{B})$ in each choice set. The opt-out option is often employed in non-hypothetical CE for imitating real-world purchase decisions (Grebitus et al., 2013), thus enhancing the accuracy of estimates (Alfnes et al., 2006). Given the literature above, three options are shown in Figure 2.

There were $96(3 \times 4 \times 2 \times 4)$ profiles by a full factorial design using Ngene 1.1 software (ChoiceMetrics), and the profiles grew exponentially for two compared alternatives in a choice set. It is impossible for the respondents to evaluate the entire choice set. Fractional factorial design was required to minimize the number of choice sets while maintaining the efficiency of the representatives (Kessels et al., 2006). After optimal design, 36 choice scenarios were generated with $91.92 \%$ of D-efficiency, $0.054 \mathrm{D}$ error, and 0.062 A error. 36 choice scenarios were divided into six blocks and each block contained six choice tasks. There were six versions of the questionnaire in this study. A respondent could only answer one questionnaire. The Chinese version of the questionnaire was used in the survey study.

To determine consumer trust in organic labels, respondents were required to answer four items derived from $\mathrm{Wu}$ (2012): 'I trust in the certification procedure of organic food and organic labels,' 'Do you believe that organic food in the market is produced in accordance with certain standards,' 'If I see an organic label on the front of the pack, I believe that this product is organic,' and 'I trust in the organic labels of other countries.' All items were rated on a five-point Likert scale from 1 for 'absolutely no trust' to 5 for 'absolutely trust'. Enlightened by previous studies, subjective knowledge was relative to actual consumption decisions (Hoek et al., 2017; Pieniak et al., 2010). Three items about subjective knowledge from a study about organic vegetables by Pieniak et al. (2010) were adopted: 'Compared with people around, I know a lot of foods with both characteristic of environmentally friendly and healthy,' 'I can evaluate whether food is environmentally friendly and healthy,' and 'People around me think I am an expert in food environmental and healthy attributes.' The degree of these three items was also rated from 1 for 'completely disagree' to 5 for 'completely agree'. The indices of the respondents' trust and subjective knowledge of organic foods were measured by the average scores of the aforementioned items.

\subsection{Data collection}

Investigation into Oolong tea should focus on target consumers because Oolong tea buyers pay more attention to the quality and safety aspects of Oolong tea. Oolong tea consumers are mainly located in Fujian and Guangdong Provinces (Chen and Yang, 2017). Thus, our face-to-face investigation was conducted in Fuzhou and Guangzhou cities, which are the respective capitals of the aforementioned provinces. Shopping online is a popular way to buy Oolong tea. As respondents from different cities can help us to draw generalized

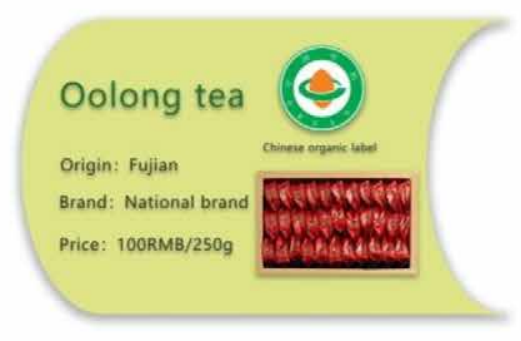

Option A

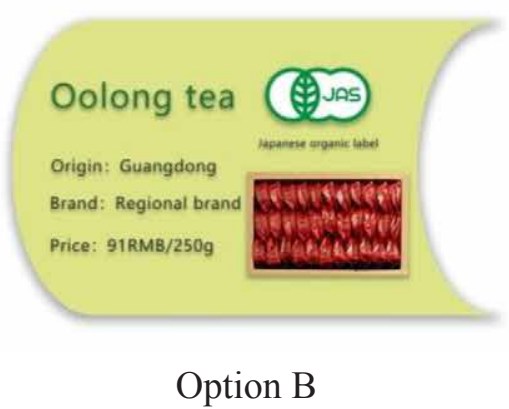

Option B
Neither option A nor option B

Option C

Figure 2. Example of a choice set. 
conclusions, this study also adopted online investigation. Several graduate students in training went to three real stores selling Oolong tea in Fuzhou city between May and June 2019. The staff helped the investigators invite consumers who were buying self-drinking Oolong tea in the stores to fill out the questionnaire by scanning a QR code. After finishing the questionnaire, each respondent received a gift. The questionnaire was in sorted order to balance the number of different blocks. The same procedures were used in Guangzhou city in July 2019. During the online interview, an online store helped us to invite consumers who had bought self-drinking Oolong tea to fill out the questionnaire; people who finished the questionnaire could be given a 10-renminbi (RMB) coupon for the store. All questionnaires consisted of three parts: (a) subjective knowledge and trust test; (b) CE choices comparing alternatives; and (c) anonymous socio-demographic information about the respondents.

A total of 509 surveys were obtained in this study. This study eliminated invalid surveys based on a 'trap question.' The trap question method was employed to identify careless respondents to enhance the accuracy of results (Wang and Gao, 2017). In our questionnaires, the trap question was set to 'Please select the 'red' option in the following four options'. Researchers dropped the survey when other colors were selected. Finally, the remaining 450 surveys ( $88.4 \%$ of total) were used for the next estimation.

\subsection{Models}

According to the Lancaster consumer theory (Lancaster, 1966), consumer utility is derived from product attributes rather than the product itself. Furthermore, the random utility theory assumes that utility consists of observable representatives and unobservable random error terms (McFadden, 1973). Consumers choose between alternatives, which are bundled attributes in a choice set, for the highest utility. Such a relationship expressed in a mathematical way is:

$$
U_{n i t}=V_{n i t}\left(\beta_{n}\right)+\varepsilon_{n i t}=\delta(A S C)+\alpha_{n}\left(X_{i}\right)+\gamma_{n}\left(-P_{i}\right)+\varepsilon_{n i t}
$$

Where $U_{n i t}$ represents the utility of consumer $n$ given alternative $i$ in choice set $t ; V_{n i t}\left(\beta_{n}\right)$ is the observable utility of parameter $\beta_{n}$, while $\varepsilon_{n i t}$ is the random error. The parameter vector $\beta_{n}=\left(\delta, \alpha_{\mathrm{n}}, \gamma_{\mathrm{n}}\right)$ is the degree of consumer $n$ 's preference for each attribute; ASC indicates the 'none' option when the value is 0 , and the value of 1 represents the given compared choice scenarios.

In discrete choice modeling, different hypotheses of the random error distribution and heterogeneity will lead to different models. The multinomial logit (MNL) model is the basic form of logit modeling. The MNL model assumes that all respondents share a homogeneous preference for the product attributes (Louviere $e t$ al., 2000). Another logit model called the random parameter logit (RPL) model relaxes the hypothesis across respondents (Train, 2009). A generalized multinomial logit (G-MNL) model has also been used to investigate consumer preferences for different food attributes (Fiebig et al., 2010; Liu et al., 2019). This study specified MNL, RPL, and G-MNL models to evaluate consumer preferences for organic tea.

In this study, the main effect of the attributes was determined using Equation 2. The place of origin was a nominal variable, so that Guangdong (GD) and Taiwan (TW) were used as dummy variables compared with the baseline of Fujian. CHIL, JAPL, and USL were the categorical variables, and the 'none' label was used as the baseline. NAB was set as basic category compared to the RGB. Price was the metric variable in accordance with the four price levels designated in the experiment. The utility function model is expressed by Equation 2:

$$
\begin{aligned}
& U_{n i t}=A S C+\beta_{1} \text { Price }_{n i t}+\beta_{2 n} G D_{n i t}+\beta_{3 n} T W_{n i t}+\beta_{4 n} C H I L_{n i t}+\beta_{5 n} J A P L_{n i t}+\beta_{6 n} U S L_{n i t} \\
& +\beta_{7 n} N A B_{n i t}+\varepsilon_{n i t}
\end{aligned}
$$

where ASC is the opt-out option and the coefficients from $\beta_{1}$ to $\beta_{7 n}$ are the parameter vectors of the attributes estimated. 
For the interaction effects of the attributes, Tru and Sub were the explanatory variables representing consumer trust and subjective knowledge about organic labels, respectively. Indices of these two attitudinal variables were created by the mean values of the item scores. The utility function with interaction is expressed by Equation 3:

$$
\begin{aligned}
& U_{n i t}=A S C+\beta_{1} \text { Price }_{\text {nit }}+\beta_{2 n} G D_{n i t}+\beta_{3 n} T W_{n i t}+\beta_{4 n} C H I L_{n i t}+\beta_{5 n} J A P L_{n i t} \\
& +\beta_{6 n} U S L_{n i t}+\beta_{7 n} N A B_{n i t}+\beta_{8 n}\left(G D_{n i t} \times T r u_{n}\right)+\beta_{9 n}\left(T W_{n i t} \times T r u_{n}\right)+\beta_{10 n}\left(C H I L_{n i t} \times T r u_{n}\right) \\
& +\beta_{11 n}\left(J A P L_{n i t} \times T r u_{n}\right)+\beta_{12 n}\left(U S L_{n i t} \times T r u_{n}\right)+\beta_{13 n}\left(N A B_{n i t} \times T r u_{n}\right)+\beta_{14 n}\left(G D_{n i t} \times S u b_{n}\right) \\
& +\beta_{15 n}\left(T W_{n i t} \times S u b_{n}\right)+\beta_{16 n}\left(C H I L_{n i t} \times S u b_{n}\right)+\beta_{17 n}\left(\operatorname{SAPL}_{n i t} \times S u b_{n}\right)+\beta_{18 n}\left(U S L_{n i t} \times S u b_{n}\right) \\
& +\varepsilon_{n i t}
\end{aligned}
$$

Consumer $n$ 's WTP for attribute $x$ is estimated by Equation 4:

$$
W T P_{n}=\beta_{n x} / \beta_{n p}
$$

where $\beta_{n x}$ is the coefficient of non-price attribute $x$ and $\beta_{n p}$ is the coefficient of price attribute $n p$.

\section{Results}

\subsection{Socio-demographics of consumers}

The socio-demographics of the consumers are presented in Table 2. The results show that female respondents slightly exceeded men in number, unlike the results of some studies on orange juice (Gao et al., 2019) and rice consumption (Wang and Gao, 2017), in that Chinese females are the primary shopper in the household. Respondents 25-34 years old occupied the largest proportion (40.44\%), followed by 35-44 years old (25.33\%), and under 24 years old (22.22\%). This implies that younger consumers prefer Oolong tea more than older consumers (over 45 years old). Most respondents had a bachelor's or an associate degree. The monthly personal income of one-fifth of the respondents was 4,000-5,999 RMB and less than 2,000 RMB. The remainder of the monthly personal income levels $(2,000-3,999,6,000-7,999,8,000-9,999,10,000-14,999$, and $\geq 15,000)$ were around $12 \%$. This implies that consumers of different income levels all purchased Oolong tea. Beyond that, almost all of the consumers had more than three members in their households.

Two attitudinal aspects including trust and subjective knowledge were detected using questionnaires. All item scores are exhibited in Table 3. Using a Likert five-point scale, consumers showed an average value of 3.31 for trust in organic labels and a value of 3.22 for subjective knowledge tests. In the following, these two indices were used in a conjoint regression to detect their interaction effects with the attributes.

\subsection{Main effect}

The results of the three regression methods are shown in Table 4, which were calculated using Stata 15.0 software (StataCorp LLC, College Station, TX, USA). The coefficient of tau is significantly positive, which indicates that there was a discrepancy in the consumers' value of the various attributes. All coefficients of the chosen attributes in the models are statistically significant at the $10 \%$ level. Except for price, the coefficients of the other attributes were statistically significant at the $1 \%$ level. These results imply that place of origin, organic label, brand, and price were all significant factors. The ASC variable as the opt-out option means that consumers do not choose any given alternative, and this result implies that it would reduce consumers' utility. The coefficient of the price variable is significantly negative in the three models, which means increasing the price has a negative influence on consumers' utility. As for the place of origin variable, the coefficients were both significantly negative, implying that people had a lower preference for the Oolong tea produced in Guangdong and Taiwan. Furthermore, people disliked Oolong tea from Guangdong more. The 'none' organic label was used as the baseline for the organic label variable, and the results imply that people showed a preference for the organic label. The coefficients of the three organic labels were all 
Table 2. Socio-demographic and economic characteristics of the sample.

\begin{tabular}{llcc}
\hline Variable & Definition & Frequency $(\mathbf{n = 4 5 0})$ & Percentage \\
\hline Gender & Male & 190 & $42.22 \%$ \\
Age (years) & Female & 260 & $57.78 \%$ \\
& $\leq 24$ & 100 & $22.22 \%$ \\
& $25-34$ & 182 & $40.44 \%$ \\
& $35-44$ & 114 & $25.33 \%$ \\
& $45-54$ & 46 & $10.22 \%$ \\
& $55-64$ & 5 & $1.11 \%$ \\
Education & $\geq 65$ & 3 & $0.67 \%$ \\
& High school degree or lower & 23 & $5.11 \%$ \\
& Bachelor's degree or associate degree & 287 & $63.78 \%$ \\
Monthly personal income (RMB ${ }^{1}$ ) & Post-graduate degree & 140 & $31.11 \%$ \\
& $\leq 2,000$ & 85 & $18.89 \%$ \\
& $2,000-3,999$ & 52 & $11.56 \%$ \\
& $4,000-5,999$ & 94 & $20.89 \%$ \\
& $6,000-7,999$ & 55 & $12.22 \%$ \\
& $8,000-9,999$ & 51 & $11.33 \%$ \\
& $10,000-14,999$ & 55 & $12.22 \%$ \\
& $\geq 15,000$ & 58 & $12.89 \%$ \\
& $\leq 2$ & 35 & $7.78 \%$ \\
Members of household (persons) & 3 & 155 & $34.44 \%$ \\
& 3 & 124 & $27.56 \%$ \\
& & 136 & $30.22 \%$ \\
\hline
\end{tabular}

${ }^{1} 1 \mathrm{USD}=6.99 \mathrm{RMB}$.

Table 3. Scores of attitudinal questions.

\begin{tabular}{llllll}
\hline Attitude 1 & Item & Mean $\left(\mathbf{S D}^{\mathbf{1}}\right)$ & Attitude 2 & Item & Mean $\mathbf{S D D}^{\mathbf{1}} \mathbf{)}$ \\
\hline Trust & Trust Q1 & $3.43(0.81)$ & Subjective & Sub Q1 & $3.42(0.86)$ \\
& Trust Q2 & $3.05(0.79)$ & knowledge & Sub Q2 & $3.44(0.80)$ \\
& Trust Q3 & $3.38(0.79)$ & & Sub Q3 & $2.82(0.98)$ \\
& Trust Q4 & $3.39(0.79)$ & & & $3.22(0.73)$ \\
\hline
\end{tabular}

${ }^{1} \mathrm{SD}=$ standard deviation.

positively significant at the $1 \%$ level. Organic labels could enhance the utility of consumers, among which, the one most preferred by consumers was the CHIL. In addition, although drinking Oolong tea is a regional habit, NAB was preferred more by consumers. In general, the organic label was the most important attribute among the attributes chosen.

\subsection{Main effect with interaction in trust and subjective knowledge}

This section investigates the conjoint effect of trust in the organic label and subjective knowledge about health and environment with the given attributes; the results are presented in Table 4. The interaction of trust with the main attributes show that the conjoint effects of trust with the three organic labels are positively significant at the 5\% level. This indicates that more people showed trust in organic labels, the more they preferred organic labels. In the MNL model, the coefficients of trust's interaction with the CHIL, JAPL, and USL variables were $0.359,0.312$, and 0.287 , respectively. The likelihood of buying Oolong tea with 


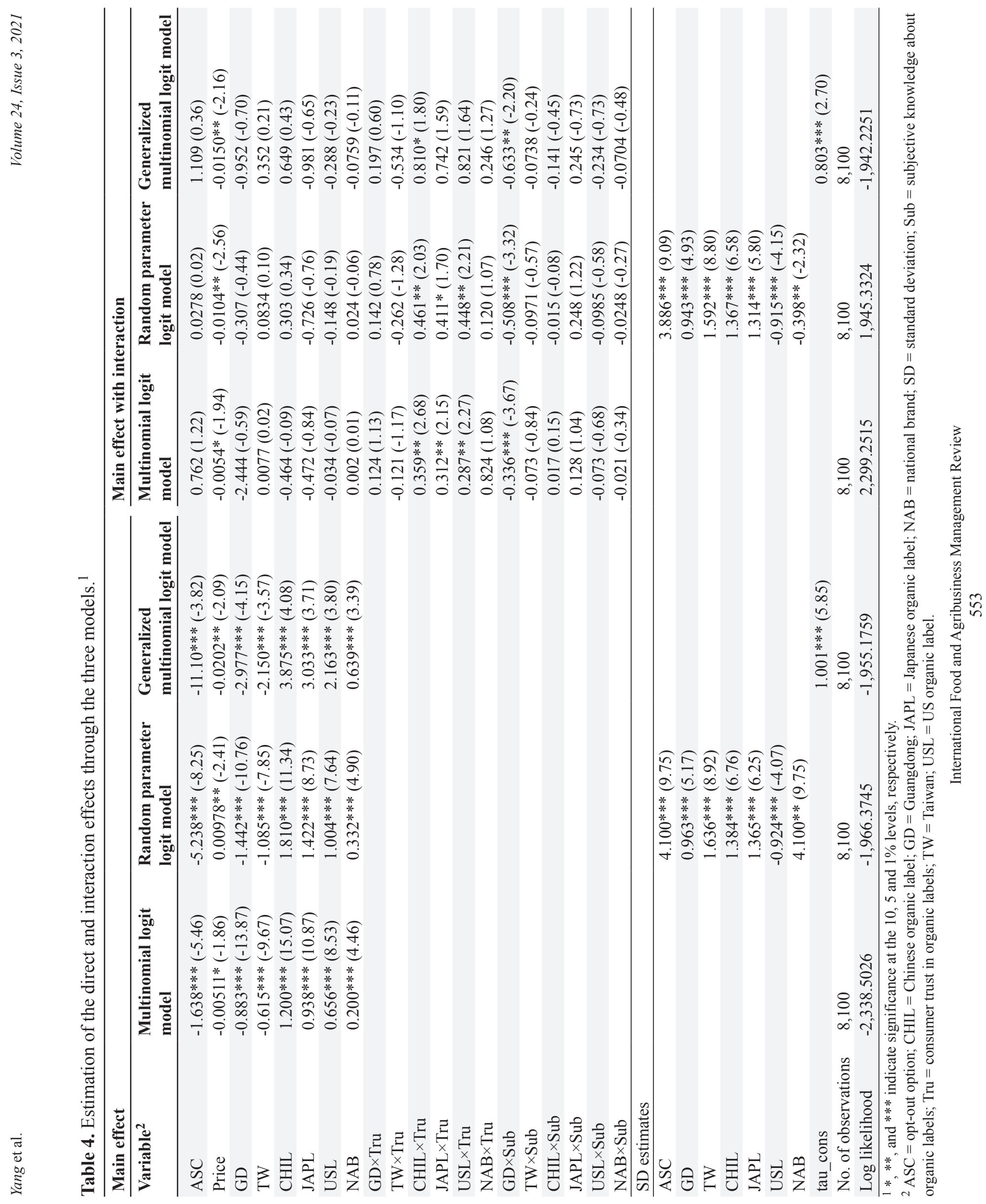


CHIL was the highest. Products with USL ranked last, yet USL still improved the preference for Oolong tea compared to the conventional one. In the RPL model, when considering heterogeneity, people with higher trust in organic labels still preferred CHIL compared to USL and JAPL. However, in this model, people preferred USL (0.448) more than JAPL (0.411). In the G-MNL model, the only coefficient of trust with CHIL was statistically significant at the $10 \%$ level. Taking the three models into consideration, CHIL played a more important role in influencing people to buy Oolong tea. On the other hand, only GD $\times$ Sub was negatively significant among the six conjoint items in the three models for the interaction between subjective knowledge and the chosen attributes. This means that people with higher subjective knowledge were less likely to buy Oolong tea from Guangdong. In addition, the heterogeneity preferences for the organic label and the brand attributes were not significant in all three models.

\subsection{Interaction between the main effect with socio-demographics}

In many previous studies, income, education, and social norms could have a significant impact on the consumption of organic food (Qi and Ploeger, 2019; Yadav and Pathak, 2016). Thus, this study verified the effects of socio-demographics on preferences for the attributes. Based on the principle of higher log likelihood and lower AIC and BIC, the RPL model was used as the representative among the three models in this sub-section. The interaction effects of the socio-demographics and the main effect chosen using the RPL model are shown in Supplementary Table S1. This study analyzed the results from the RPL model, which show that the coefficients of Income $\times$ CHIL and Age $\times$ CHIL are negatively significant. This implies that Oolong tea with CHIL could attenuate the utility of older and higher income consumers. This might be because older consumers have less trust in CHIL, and higher income people recognize imported food as safer and higher quality (Xie et al., 2011). The Age $\times G D$ variable was negatively significant, implying that older people are less likely to buy Oolong tea from Guangdong. Conversely, the coefficient of the Edu $\times$ TW variable indicates that well-educated people are more likely to buy Oolong tea from Taiwan.

\subsection{Willingness to pay}

Table 5 demonstrated the WTP for various levels of different attributes, including the mean and the 95\% confidence interval values of premium or discount through the three models. All results in Table 5 were statistically significant from zero at the $1 \%$ level. This study also focused on the results from the RPL model, because the RPL model had a higher log likelihood and lower AIC and BIC.

Compared with Oolong tea from Fujian, Chinese consumers showed a negative preference for Oolong tea from Guangdong and Taiwan, with a lower WTP of \$21.08 and \$15.87, respectively. Consumers especially discounted the Oolong tea from Guangdong more than that from Taiwan. A potential reason for this phenomenon is that Guangdong Oolong tea is less well-known. Thus, consumers would assume that

Table 5. Willingness to pay for place of origin, organic label, and brand. ${ }^{1}$

\begin{tabular}{|c|c|c|c|c|c|c|}
\hline \multirow[t]{2}{*}{ Attributes } & \multicolumn{2}{|c|}{ Multinomial logit model } & \multicolumn{2}{|c|}{$\begin{array}{l}\text { Random parameter } \\
\text { logit model }\end{array}$} & \multicolumn{2}{|c|}{$\begin{array}{l}\text { Generalized multinomial } \\
\text { logit model }\end{array}$} \\
\hline & $\begin{array}{l}\text { Mean } \\
\text { (US\$) }\end{array}$ & CI $[5 \%, 95 \%]$ & Mean (US\$) & CI $[5 \%, 95 \%]$ & Mean (US\$) & CI $[5 \%, 95 \%]$ \\
\hline GD & -24.73 & {$[-50.79,1.34]$} & -21.08 & {$[-38.04,-4.12]$} & -21.10 & {$[-37.92,-4.29]$} \\
\hline TW & -17.23 & {$[-36.31,1.86]$} & -15.87 & {$[-29.40,-2.34]$} & -15.24 & {$[-28.09,-2.39]$} \\
\hline CHIL & 33.58 & {$[-1.66,68.81]$} & 26.47 & {$[4.87,48.08]$} & 27.46 & {$[-5.40,49.52]$} \\
\hline JAPL & 26.26 & {$[-1.90,54.42]$} & 20.79 & {$[3.36,38.22]$} & 21.50 & {$[3.37,39.62]$} \\
\hline USL & 18.36 & {$[-1.87,38.60]$} & 14.68 & {$[1.97,27.39]$} & 15.33 & {$[2.10,28.56]$} \\
\hline NAB & 5.59 & {$[-0.62,11.81]$} & 4.86 & {$[0.65,9.07]$} & 4.53 & {$[0.66,8.40]$} \\
\hline
\end{tabular}

${ }^{1} \mathrm{CI}=$ confidence interval; GD = Guangdong; JAPL = Japanese organic label; NAB = national brand; TW $=$ Taiwan; USL $=$ US organic label. 
Oolong tea from Guangdong is of lower quality and taste (Mei et al., 2012). As for the organic label, Oolong tea with an organic label is highly valued by Chinese consumers. Among the three organic labels, WTP for CHIL, JAPL, and USL was \$26.47, \$20.79, and \$14.68, respectively, much greater than for conventional products. When the premium percentage of organic Oolong tea to the conventional one was considered, people would pay $203 \%$ more for CHIL, $160 \%$ more for JAPL, and 113\% more for USL. The results in this study were consistent with previous studies in that consumers showed a positive and higher value for organic labels (Quan et al., 2018). However, CHIL was the most valued by consumers in this study, whereas WTP for CHIL ranked last in other studies (Chen et al., 2019a; Yin et al., 2016). Additionally, consumers preferred NAB to the RGB. The premium for NAB is $\$ 4.86$. NAB was recognized as more credible in terms of quality and safety, thus satisfying the demands of consumers.

\section{Discussion}

Chinese consumers showed a greater demand for safe and sustainable foods after the emergence of food scandals (Zhang et al., 2014). Organic food is usually perceived as a safe and environmentally friendly product by developed-country counterparts (Loebnitz and Aschemann-Witzel, 2016). In this study, organic labels can enhance the utility of consumers, and positive attitudes from consumers were detected using the CE method. This result is consistent with other studies (Quan et al., 2018; Yu et al., 2014), i.e. Chinese people have a positive preference for organic food. In several previous studies, researchers examined consumer preferences for organic labels from different countries or regions, and the results demonstrated that Chinese consumers preferred organic labels from developed countries compared to CHIL (Chen et al., 2019a; Li et al., 2015; Wu et al., 2014). Yin et al. (2016) also revealed that consumers preferred tomatoes with European Union (EU) organic labels than those with CHIL. In addition, research analyzing EU, Brazilian, Japanese, and CHILs on vegetables was performed, and the results showed that the WTP rankings for these organic labels from high to low were EU, Brazilian, Japanese, and CHILs (Li et al., 2015). Similarly, consumers preferred infant milk powder with USL to those with CHILs (Yin et al., 2018b). However, in this research, WTP for CHIL was much higher than that of JAPL and USL. Some studies confirmed that Chinese consumers did not always prefer foreign products unless a more symbolic value was attached (Ehmke et al., 2008; Wang et al., 2018; Zhou and Hui, 2003). This study demonstrated that the 'foreign halo' is attenuated on uniquely Chinese products such as Oolong tea. These inconsistent conclusions imply that Chinese consumers' preference for different organic labels is very much associated with the product category. Another potential reason for people preferring CHIL to organic labels from other countries is familiarity. Hoek et al. (2017) pointed out the importance of familiarity in consumers' point-of-purchase actions. Product familiarity determines the consumers' positive response to sustainable food choices. CHIL is preferred because China is the largest producer of tea and domestic certification of tea has been recognized as more reliable in China. Similarly, Japan also has a culture of drinking tea while the US does not, so the respondents were more familiar with Japanese tea culture and therefore put a higher value on JAPL. In addition, the focus group discussions in Yin et al. (2018b) indicated that participants from different areas tended to prefer their local foods. Thus, the preference for local tea might also extend to local certifications, such as CHIL versus foreign organic labels. Oolong tea from Fujian occupied the highest percentage of Oolong tea in the market, thus people were more familiar with Fujian Oolong tea and recognized it as the highest quality. On the contrary, Guangdong Oolong tea accounts for a lower market share, thus people might be unfamiliar with this product and put a lower value on Oolong tea from Guangdong. This further highlights that familiarity affects consumers' preferences and purchase intentions. Compared with the RGBs, NABs are more capable of production control, which was recognized as representing a higher quality assurance by consumers, especially after the food safety scandals. Thus, NAB had a positive effect on consumers' preferences.

The effect of consumers trust in China's food regulations or certifications has been an emerging issue in recent several studies (Chen et al., 2019a; Liu et al., 2019; Zhang et al., 2014). The demand for organic food is significantly related to the food safety issue ( $\mathrm{Li}$ et al., 2020). This study measured the scale of trust in organic labels and the results indicate that people are inclined to trust organic labels. The interaction between trust and organic labels confirmed that trust has a positive effect on consumer preferences for various 
organic labels. This conclusion is consistent with the study by Chen et al. (2019a) and Yin et al. (2019a). At an earlier stage, the majority of Chinese consumers considered the government as a faithful information source (Liu et al., 2013). However, repeatedly exposed food scandals have shaken Chinese consumer trust in food safety regulations by the government (Liu et al., 2019) and attenuated their trust in food certifications (Chen, 2013; Yin et al., 2019a; Yu et al., 2014). In previous studies, Chinese consumers illustrated a lower preference and WTP for CHIL because of a lack of faith (Chen et al., 2019a; Li et al., 2015; Xu et al., 2015). Lack of trust is also thought to be one of the most significant barriers for the development of the organic food market (Nuttavuthisit and Thøgersen, 2017; Vega-Zamora et al., 2019). In this research, Chinese consumers presented a positive evaluation of Chinese organic certifications. This is a significant reason why people prefer CHIL. Thus, an effort should be put into promoting the credence of organic food. It is imperative to push for firm and consistent standards in organic foods so that consumers can confidently trust in these products (Nuttavuthisit and Thøgersen, 2017). The levels of trust in organic foods could be managed through the functionality and authenticity dimensions (Vega-Zamora et al., 2019). Chinese consumers are willing to pay a premium for products with CHIL, which provides a better opportunity for Chinese producers. Tea companies like to make different kinds of organic certifications to enter domestic markets (Chen et al., 2019a) and display higher quality (Bai et al., 2013). Thus, CHIL could be used alone in the domestic market.

The final score of subjective knowledge was slightly over the median score, which indicates that people have a relatively high subjective knowledge about health and environmental issues. However, after interaction with the attributes chosen, it was not a key factor in determining preference or purchase intention. A higher level of knowledge might have shown a correlation but not necessarily causation for buying sustainable food, e.g. enhancing the educational level did not change the consumers purchase decisions regarding sustainable alternatives (Garnett et al., 2015). This study also considered the role of socio-demographics on choice. Education, income, and age separately had little influence on Oolong tea purchases. Higher income and older people were more reluctant to consume organic food with CHIL. It seems that richer and older consumers have a more stable bias for Chinese food due to previous food scandals. Yu et al. (2014) revealed that younger people are willing to pay more than older consumers for green/organic food. Higher-educated consumers seem to prefer organic labels from Taiwan. A potential reason for this is that products from Taiwan gained a good reputation for quality in earlier years, which might reflect on the higher value for labels or certifiers from Taiwan among well-educated consumers. However, socio-demographics alone are not enough to explain the discrepancy in consumption behaviors (Hoek et al., 2017). Many other aspects (i.e. psychographic, habit, and intrinsic attributes of the product itself) need to be considered to fully measure the choice patterns (De Jonge et al., 2015; Grunert et al., 2015).

The limitations of this study are as follows. First, Oolong tea is only one kind of tea product. Studies can analyze other kinds of tea to make more general conclusions. Second, this study focuses on two provinces in China, thus the sample is limited. It might be expanded to other regions. Third, the average price of Oolong tea is generally higher than other kinds of tea and consumers of Oolong tea might be at a higher income level, so that consumer price sensitivity is not as apparent as in other studies (Aschemann-Witzel and Zielke, 2017; Xie et al., 2015; Yin et al., 2010). Last, the higher WTP for organic labels might change when different foods are involved. Thus, to further investigate consumers' attitudes and preference for organic labels, more kinds of food should be considered.

\section{Conclusions and implications}

This study focused on consumer preferences for organic labels among Chinese consumers. The research chose Oolong tea, a real product in the organic market to conduct this study. Using a CE, many significant factors that influence consumers' purchase intentions were analyzed. It was confirmed that organic labels have a positive influence on consumer preferences in China. Chinese consumers are more inclined to trust domestic organic certifications for tea than those from other countries. In addition, the place of origin was also a significant factor that impacted consumers' evaluation of products. As the largest origin for Oolong tea, Fujian Province was inferred as a better quality cue by consumers. NAB was also a positive factor 
influencing the preference for Oolong tea. The highest premium for an organic label was about $203 \%$ for CHIL, followed by JAPL (160\%), and USL (113\%). Consumers would also pay a 4.87-dollar premium for Oolong tea with NAB compared to the RGB. In addition, consumers showed a higher trust in organic certification than the median level. People with higher trust were more likely to purchase products attached with CHIL, which indicates that enhancing trust in organic certification could lead to a higher WTP for organic food. This study also considered subjective knowledge about the environment and health and found that people with higher scores in this item preferred Oolong tea from Fujian Province. The socio-demographics were not very significant to organic Oolong tea purchasing decisions compared to the other attributes. Higher income and older people were less likely to choose CHIL, while well-educated people were more inclined to purchase Oolong tea from Taiwan.

This study proposed some policy implications for both policymakers and tea producers in China. First, Chinese consumers showed a highly positive value for organic Oolong tea. This is beneficial for sustainable development. As tea planters turn to sustainable production, they can generate profits since consumers will pay a premium for organic Oolong tea. Thus, the government should encourage tea producers and factories to make Chinese organic certifications, which is beneficial to consumers and factories. Second, no matter where the Oolong tea was produced, Chinese labels were more attractive in the domestic organic food market. Since companies are inclined to make foreign labels, especially certifications from developed regions, the results of this study indicate that a Chinese organic label is sufficient for the organic Oolong tea market in China. This provides a better opportunity for Chinese producers to cut costs on certifications. Third, this study illustrates the importance of trust in organic labels when eliciting consumer attitudes and WTP for Oolong tea. To generate growth in the consumption of organic Oolong tea, the Chinese government should adopt a responsible attitude to reduce food fraud and thus enhance the degree of consumer trust in organic food.

\section{Supplementary material}

Supplementary material can be found online at https://doi.org/10.22434/IFAMR2020.0113

Table S1. Interaction effects of the socio-demographics and main effects through RPL model.

\section{Acknowledgements}

This research was funded by the Ministry of Education Humanities and Social Sciences Research Project (19YJCZH203); the Major Project Funding for Social Science Research Base in Fujian Province Social Science Planning (FJ2018JDZ062); the Fujian Planning Project of Science and Technology (2020R0036); Natural Science Foundation of Fujian Province (2020J01590); the FAFU Foundation for Distinguished Young Scholars (xjq201824); the Fujian Provincial Social Science Research Base for Ecological Civilization (KXJD1815A); the Guangdong Planning Projects of Philosophy and Social Science (GD16YGL03); Natural Science Foundation of Guangdong Province (2017A030313395).

\section{Conflicts of interest}

The authors declare no conflict of interest.

\section{References}

Albersmeier, F., H. Schulze and A. Spiller. 2010. System dynamics in food quality certifications: development of an audit integrity system. International Journal on Food System Dynamics 1(1): 69-81.

Alfnes, F., A.G. Guttormsen, G. Steine and K. Kolstad. 2006. Consumers' willingness to pay for the color of salmon: a choice experiment with real economic incentives. American Journal of Agricultural Economics 88(4): 1050-1061. 
Aschemann-Witzel, J. and S. Zielke. 2017. Can't buy me green? A review of consumer perceptions of and behavior toward the price of organic food. Journal of Consumer Affairs 51(1): 211-251.

Auger, P. and T.M. Devinney. 2007. Do what consumers say matter? The misalignment of preferences with unconstrained ethical intentions. Journal of Business Ethics 76(4): 361-383.

Bai, J., C. Zhang, and J. Jiang. 2013. The role of certificate issuer on consumers' willingness-to-pay for milk traceability in China. Agricultural Economics 44(4-5): 537-544.

Bekele, G.E., D. Zhou, A.A. Kidane and A.B. Haimanot. 2017. Analysis of organic and green food production and consumption trends in China. American Journal of Theoretical and Applied Business 3(4): 64-70.

Boncinelli, F., A. Dominici, F. Gerini and E. Marone. 2019. Consumers wine preferences according to purchase occasion: personal consumption and gift-giving. Food Quality and Preference 71: 270-278.

Bryła, P. 2016. Organic food consumption in Poland: motives and barriers. Appetite 105: 737-746.

Carvalho, F.P. 2006. Agriculture, pesticides, food security and food safety. Environmental Science \& Policy 9(7-8): 685-692.

Chen, M., Y. Wang and S. Yin. 2019b. Research on the reformation path of China's food safety certification policy: from the perspective of consumer preference. Economy and Management Publishing House, Beijing, China.

Chen, M., Y. Wang, S. Yin, W. Hu and F. Han. 2019a. Chinese consumer trust and preferences for organic labels from different regions. British Food Journal 12(7): 1521-1535.

Chen, P., Y. Wang, X. Guan, J. Huang, P. An, H. Jiang, Y. Ma and J. Yang. 2016. A survey on tea consumption behavior of Fujian province. Issues of Forestry Economics 36(4): 369-372.

Chen, Q. and J. Yang. 2017. Research on production efficiency and affecting factors of Oolong tea producing areas by Fujian and Taiwan province. Asia-pacific Economic Review 34(4): 101-106. https://doi. org/10.16407/j.cnki.1000-6052.2017.04.014

Chen, W. 2013.The effects of different types of trust on consumer perceptions of food safety. China Agricultural Economic Review 5(1): 43-65.

Chen, X., D. Wang, J. Li, T. Xu, K. Lai, Q. Ding, H. Lin, L. Sun and M. Lin. 2020. A spectroscopic approach to detect and quantify phosmet residues in Oolong tea by surface-enhanced Raman scattering and silver nanoparticle substrate. Food Chemistry 312: 126016.

Chen, Y.L., J. Duan, Y.M. Jiang, J. Shi, L. Peng, S. Xue and Y. Kakuda. 2010. Production, quality, and biological effects of oolong tea (Camellia sinensis). Food Reviews International 27(1): 1-15.

Daugbjerg, C., S. Smed, L.M. Andersen and Y. Schvartzman. 2014. Improving eco-labelling as an environmental policy instrument: knowledge, trust and organic consumption. Journal of Environmental Policy \& Planning 16(4): 559-575.

De Jonge, J., I.A. Van der Lans and H.C. Van Trijp. 2015. Different shades of grey: compromise products to encourage animal friendly consumption. Food quality and Preference 45: 87-99.

Ehmke, M.D., J.L. Lusk and W. Tyner. 2008. Measuring the relative importance of preferences for country of origin in China, France, Niger, and the United States. Agricultural Economics 38(3): 277-285.

Enneking, U., C. Neumann and S. Henneberg. 2007. How important intrinsic and extrinsic product attributes affect purchase decision. Food Quality and Preference 18(1): 133-138.

Fiebig, D.G., M.P. Keane, J. Louviere and N. Wasi. 2010. The generalized multinomial logit model: accounting for scale and coefficient heterogeneity. Marketing Science 29(3): 393-421.

Gao, Z., X. Yu, C. Li and B.R. McFadden. 2019. The interaction between country of origin and genetically modified orange juice in urban China. Food Quality and Preference 71: 475-484.

Garnett, T., S. Mathewson, P. Angelides and F. Borthwick. 2015. Policies and actions to shift eating patterns: what works. Foresight 515(7528): 518-522.

Ghvanidze, S., N. Velikova, T.H. Dodd and W. Oldewage-Theron. 2016. Consumers' environmental and ethical consciousness and the use of the related food products information: the role of perceived consumer effectiveness. Appetite 107: 311-322.

Goetzke, B., S. Nitzko and A. Spiller. 2014. Consumption of organic and functional food. A matter of wellbeing and health? Appetite 77: 96-105.

Grebitus, C., J.L. Lusk and R.M. Nayga Jr. 2013. Explaining differences in real and hypothetical experimental auctions and choice experiments with personality. Journal of Economic Psychology 36: 11-26. 
Greiner, R., M. Bliemer and J. Ballweg. 2014. Design considerations of a choice experiment to estimate likely participation by north Australian pastoralists in contractual biodiversity conservation. Journal of Choice Modelling 10: 34-45.

Grunert, K.G., S.M. Loose, Y. Zhou and S. Tinggaard. 2015.Extrinsic and intrinsic quality cues in Chinese consumers' purchase of pork ribs. Food quality and Preference 42: 37-47.

Gunathilaka, R. and G.A. Tularam. 2016. The tea industry and a review of its price modelling in major tea producing countries. Journal of Management and Strategy 7: 21-36.

Hoek, A., D. Pearson, S. James, M. Lawrence and S. Friel. 2017. Healthy and environmentally sustainable food choices: consumer responses to point-of-purchase actions. Food Quality and Preference 58: 94-106.

Kessels, R., P. Goos and M. Vandebroek. 2006. A comparison of criteria to design efficient choice experiments. Journal of Marketing Research 43(3): 409-419.

Krystallis, A. and G. Chryssohoidis. 2005. Consumers' willingness to pay for organic food. Factors that affect it and variation per organic product type. British Food Journal 107(5): 320-343.

Lähteenmäki, L. 2013. Claiming health in food products. Food Quality and Preference 27(2): 196-201.

Lancaster, K.J. 1966. A new approach to consumer theory. Journal of Political Economy 74(2): 132-157.

Lassoued, R. and J.E. Hobbs. 2014. The determinants of consumer confidence in credence attributes: trust in the food system and in brands. Food Policy 52: 99-107.

Li, R., C. Lee, Y. Lin and C. Liu. 2020. Chinese consumers' willingness to pay for organic foods: a conceptual review. International Food and Agribusiness Management Review 23(2): 173-188.

Li, X., Y. Xu, S. Yin and Y. Gao. 2015. Consumers' willingness to pay for different organic certification labels: the pratical research based on 752 consumers sample in Shandong Province. China Soft Science 30(4): 49-56.

Liu, R., Z. Gao, R.M. Nayga Jr, H.A. Snell and H. Ma. 2019. Consumers' valuation for food traceability in China: does trust matter? Food Policy 88: 101768.

Liu, R., Z. Pieniak and W. Verbeke. 2013. Consumers' attitudes and behaviour towards safe food in China: a review. Food Control 33(1): 93-104.

Lockeretz, W. 2007. Organic farming: an international history. CABI, Wallingford, UK.

Loebnitz, N. and J. Aschemann-Witzel. 2016.Communicating organic food quality in China: consumer perceptions of organic products and the effect of environmental value priming. Food Quality and Preference 50: 102-108.

Louviere, J.J., D.A. Hensher and J.D. Swait. 2000. Stated choice methods: analysis and applications. Cambridge University Press, Cambridge, UK.

McFadden, D. 1973. Conditional logit analysis of qualitative choice behavior. In: P. Zarembka (ed.) Frontiers in econometrics. Academic Press, New York, NY, USA, pp. 105-142.

Mei, L., P. Lundin, M. Brydegaard, S. Gong, D. Tang, G. Somesfalean, S. He and S. Svanberg. 2012. Tea classification and quality assessment using laser-induced fluorescence and chemometric evaluation. Applied Optics 51(7): 803-811.

Mei, Y. 2020. Report on China's tea production and marketing in 2019. Available at: http://net.fafu.edu.cn/ ccyfy/15/0b/c9282a267531/page.htm (in Chinese)

Ministry of Agriculture and Rural Affairs of the People's Republic of China (Department of Agriculture). 2015. The plan to ensure zero growth in pesticide use by 2020. Available at : http://www.moa.gov. cn/ztzl/mywrfz/gzgh/201509/t20150914_4827907.htm (in Chinese)

Nuttavuthisit, K. and J. Thøgersen. 2017. The importance of consumer trust for the emergence of a market for green products: the case of organic food. Journal of Business Ethics 140(2): 323-337.

Pieniak, Z., J. Aertsens and W. Verbeke. 2010. Subjective and objective knowledge as determinants of organic vegetables consumption. Food Quality and Preference 21(6): 581-588.

Qi, X. and A. Ploeger. 2019. Explaining consumers' intentions towards purchasing green food in Qingdao, China: the amendment and extension of the theory of planned behavior. Appetite 133: 414-422.

Quan, S., Y. Zeng, X. Yu and T. Bao. 2018. WTP for baby milk formula in China: using attribute nonattendance as a priori information to select attributes in choice experiment. Agribusiness 34(2): 300-320. 
Scozzafava, G., F. Gerini, F. Boncinelli, C. Contini, E. Marone and L. Casini. 2020. Organic milk preference: is it a matter of information? Appetite 144: 104477.

Thøgersen, J. and Y. Zhou. 2012. Chinese consumers' adoption of a 'green' innovation - the case of organic food. Journal of Marketing Management 28(3-4): 313-333.

Thøgersen, J., S. Pedersen and J. Aschemann-Witzel. 2019. The impact of organic certification and country of origin on consumer food choice in developed and emerging economies. Food Quality and Preference 72: $10-30$.

Tonkin, E., S.B. Meyer, J. Coveney, T. Webb and A.M. Wilson. 2016. The process of making trust related judgements through interaction with food labelling. Food Policy 63: 1-11.

Train, K.E. 2009. Discrete choice methods with simulation. Cambridge University Press, Cambridge, UK.

Vega-Zamora M., F. Torres-Ruiz and M. Parras-Rosa. 2019. Towards sustainable consumption: keys to communication for improving trust in organic foods. Journal of Cleaner Production 216: 511-519.

Wang, E. and Z. Gao. 2017. Chinese consumer quality perception and preference of traditional sustainable rice produced by the integrated rice-fish system. Sustainability 9(12): 2282.

Wang, H., J. Chen, J. Bai and J. Lai. 2018. Meat packaging, preservation, and marketing implications: consumer preferences in an emerging economy. Meat Science 145: 300-307.

Willer, H. and J. Lernoud. 2019. The world of organic agriculture. Statistics and emerging trends 2019. Research Institute of Organic Agriculture FiBL / IFOAM Organics International, Frick, Switzerland / Bonn, Germany.

Wu, L. 2012. A study on consumers' value evaluation, and consumption choice towards low-carbon agricultural products. MSc-thesis, Economics, Nanjing Agricultural University, Nanjing, China.

Wu, L., S. Yin, Y. Xu and D. Zhu. 2014. Effectiveness of China's organic food certification policy: consumer preferences for infant milk formula with different organic certification labels. Canadian Journal of Agricultural Economics/Revue Canadienne d'Agroeconomie 62(4): 545-568.

Xie, B., L. Tingyou and Q. Yi. 2011.Organic certification and the market: organic exports from and imports to China. British Food Journal 113(10): 1200-1216.

Xie, B., L. Wang, H. Yang, Y. Wang and M. Zhang. 2015. Consumer perceptions and attitudes of organic food products in Eastern China. British Food Journal 117(3): 1105-1121.

Xu, Y., S. Yin, H. Song and L. Wu. 2015. A survey of consumers' willingness to pay: taking organic food as an example. Journal of Marketing Science 11(3): 120-138.

Yadav, R. and G.S. Pathak. 2016. Intention to purchase organic food among young consumers: evidences from a developing nation. Appetite 96: 122-128.

Yao, L., M. Zhao, Y. Cai and Z. Yin. 2018. Public preferences for the design of a farmland retirement project: using choice experiments in urban and rural areas of Wuwei, China. Sustainability 10(5): 1579.

Yin, S., F. Han, Y. Wang, W. Hu and S. Lv. 2019a. Ethnocentrism, trust, and the willingness to pay of Chinese consumers for organic labels from different countries and certifiers. Journal of Food Quality, Article ID: 8173808.

Yin, S., L. Wu, L. Du and M. Chen. 2010. Consumers' purchase intention of organic food in China. Journal of the Science of Food and Agriculture 90(8): 1361-1367.

Yin, S., M. Chen, Y. Chen, Y. Xu, Z. Zou and Y. Wang. 2016. Consumer trust in organic milk of different brands: the role of Chinese organic label. British Food Journal 118(7): 1769-1782.

Yin, S., R. Li, L. Wu and X. Chen. 2018a. Introduction to 2018 China development report on food safety. Peking University Press, Beijing, China.

Yin, S., W. Hu, Y. Chen, F. Han, Y. Wang and M. Chen. 2018b. Chinese consumer preferences for fresh produce: interaction between food safety labels and brands. Agribusiness 35(1): 53-68.

Yin, S., Y. Wang and K. Li. 2019b. Pre-certification or retrospective? The study of consumer preferences for food safety information labels and their interactive relationships. China Rural Survey 5: 127-144.

Yu, X., Z. Gao and Y. Zeng. 2014. Willingness to pay for the 'green food' in China. Food Policy 45: 80-87.

Zhang, C., J. Bai and J. Jiang. 2014. The impact of certification on consumers' willingness to pay: evidence from traceable milk. Chinese Rural Economy 8: 76-85. 
Zhang, Y., L. Jing, Q. Bai, W. Shao, Y. Feng, S. Yin and M. Zhang. 2018. Application of an integrated framework to examine Chinese consumers' purchase intention toward genetically modified food. Food Quality and Preference 65: 118-128.

Zheng, Y., X. Li and H.H. Peterson. 2013. In pursuit of safe foods: Chinese preferences for soybean attributes in soymilk. Agribusiness 29(3): 377-391.

Zhou, L. and M.K. Hui. 2003. Symbolic value of foreign products in the People's Republic of China. Journal of International Marketing 11(2): 36-58.

Zhou, Z.-Y., H. Liu and L. Cao. 2014. Food consumption in China: the revolution continues. Edward Elgar Publishing, Cheltenham, UK.

Zhu, Q., Y. Li, Y. Geng and Y. Qi. 2013. Green food consumption intention, behaviors and influencing factors among Chinese consumers. Food Quality and Preference 28(1): 279-286. 
